\title{
NATUREZA E CULTURA EM "ÍNDIOS \\ E MAMELUCOS NA EXPANSÃO PAULISTA" \\ E OS PARCEIROS DO RIO BONITO
}

Gilton Mendes dos Santos*

\section{Resumo}

Apesar de seus estilos e propósitos diferentes, "Índios e mamelucos na expansão paulista", de Sérgio Buarque de Holanda, e Os parceiros do Rio Bonito, de Antonio Candido, podem representar dois modelos epistemológicos nos quais se fundamentam as teorias da relação entre natureza e cultura: o pensamento mágico, característico das sociedades não-modernas, e o pensamento científico, típico das sociedades modernas.

Palavras-chave: Grupos sociais, natureza, cultura.

Existem momentos na vida onde a questão de saber se se pode pensar diferentemente do que se pensa, e perceber diferentemente do que se vê, é indispensável para continuar a olhar ou a refletir.

(FoUCAULT)

Este ensaio é um exercício de leitura da relação cultura-natureza nas obras "Índios e mamelucos na expansão paulista”, de Sérgio Buarque de Holanda, e Os parceiros do Rio Bonito, de Antonio Candido. A primeira publicada em 1949 e a segunda escrita em 1954 e publicada no ano de $1964 .^{1}$

A leitura tem como foco aquela dimensão do pensamento - tal como aparece nas obras em questão - que norteia a relação dos grupos sociais com o meio em que vivem. Ou seja, trata-se de um esforço de enxergar, ou melhor, de acreditar que existe uma herança do "pensamento

* Doutorando em Antropologia Social na USP.

E-mail: giltonmendes@bol.com.br 
mágico" que não estabelece uma imperativa dualidade ontológica entre sociedade e natureza. Em outros termos: aquilo que denominamos natureza, externa e oposta ao social, é, de certa forma, para a concepção dos grupos em apreço, parte componente da vida social.

"Índios e mamelucos na expansão paulista" constitui uma descrição e análise das formas de adaptação do colonizador ao meio tropical e da experiência indígena nos primeiros momentos da ocupação das terras interioranas do Brasil, matriz das formações rurais posteriores. Os parceiros do Rio Bonito objetiva a caracterização da cultura caipira através do estudo dos meios de subsistência e das formas de organização social de um agrupamento de parceiros no município paulista de Bofete.

Assim, a primeira obra forma um cenário mais geral em que a segunda figura como um caso particular. Não por acaso, em seu livro, Antonio Candido comenta o ensaio de Sérgio Buarque referindo-se a ele como uma fonte que "permite reconstruir o tipo de equilíbrio entre o grupo e o meio, característico da cultura tradicional do caipira, obtido pela elaboração original das heranças culturais que recebeu" (p. 87). Em suma, as duas obras serão aqui tomadas como contíguas e complementares, guardadas suas particularidades, seus diferentes estilos e propósitos, bem como a problemática que cada uma aborda.

Se nas primeiras páginas de "Índios e mamelucos na expansão paulista" assistimos ao encontro e à parceria de brancos colonizadores e índios, não é o mesmo que vemos nas posteriores, em que sobressai a presença dos seus descendentes - mistos daquelas formas -, na experiência social de "apreensão da natureza". Na obra Os parceiros do Rio Bonito, de Antonio Candido, por sua vez, deparar-nos-emos com o caipira, um dos tipos de descendência cultural forjado da "combinação mameluca": "a vida social do caipira assimilou e conservou os elementos condicionados pelas suas origens nômades" (p. 47).

Se, por um lado, "Índios e mamelucos na expansão paulista" explora as formas de adaptação do colonizador ao meio, através da interação deste com os nativos, Os parceiros do Rio Bonito aborda a organização social a partir das necessidades alimentares do caipira, com ênfase na relação entre o mínimo vital e o mínimo social. Na primeira sobressaem as vicissitudes do mundo natural; na segunda, a manufatura social. Naquela, a natureza aparece como condição, que condiciona; nesta, 
a natureza é meio, que possibilita. O trabalho de Sérgio Buarque tem como base as fontes secundárias, registros e relatos de viajantes, já o de Antonio Candido se sustenta sobre fontes primárias da experiência etnográfica de campo. Poderíamos dizer, ainda, que no ensaio de 1949 as personagens movimentam-se por um vasto território virgem, palmilhando-o e explorando os seus recursos naturais com escassa ou quase nenhuma tecnologia industrial, já os parceiros caipiras são atores de um outro momento histórico, tecnológico e social, dependentes em geral de bens industrializados e organizados em torno de bairros, vilas e cidades.

Em resumo, este ensaio é, na verdade, um "experimento" que propõe uma abordagem cuja perspectiva - uma reflexão sobre a relação entre cultura e natureza a partir do exposto acima - não é aquela seguida pelos autores em questão, mas que procura - parafraseando Deleuze que comenta sobre uma de suas leituras de Nietzsche - "fazer um filho por trás" destes, observando outras dimensões dessa relação.

\section{O pensamento científico: a natureza em questão}

Reputamos aos gregos as formas berçárias do pensamento científico ocidental. Diz-se que, embora a religião grega fosse tão animista quanto as outras religiões antigas, baseando-se em sacrifícios aos deuses e na intervenção divina nos negócios, a ciência grega representou um feito notável, separando a investigação das leis da natureza de quaisquer questões religiosas entre o homem e os deuses (RonAn, 1997).

No bojo desse fenômeno certamente encontra-se aquilo que Max Weber considerou um dos maiores instrumentos do conhecimento científico: o conceito. Bastava a descoberta deste para ter condição de compreender o verdadeiro sentido das coisas e dos fenômenos. Assim se baseavam as explicações naturais sobre o mundo, deduzindo as teorias subjacentes dos fatos da observação e da experiência; a verdade como realidade desvelada: a gênese da tradição metafísica ocidental.

Contudo, na sua origem, entre os pré-socráticos, o conceito de physis é bastante abrangente e suficientemente maleável para incluir a gênese de todas as coisas, o psiquismo humano, o sobrenatural, os deuses 
e a ação de seus poderes sobre os seres humanos; enfim, a "totalidade de tudo o que é", como nos atenta G. A. Bornheim, na introdução do seu livro Os filósofos pré-socráticos:

Convém chamar a atenção para um desvio em que facilmente incorre o homem contemporâneo. Posto que a nossa compreensão do conceito de natureza é muito mais estreito e pobre que a grega, o perigo consiste em julgar a physis como se os pré-socráticos a compreendessem a partir daquilo que nós hoje entendemos por natureza; nesse sentido se comprometeria o primitivo pensamento grego com uma espécie de naturalismo.

E completa, remetendo o leitor a Heidegger:

À physis pertencem o céu e a terra, a pedra e a planta, o animal e o homem, o acontecer humano como obra do homem e dos deuses, e, sobretudo, pertencem à physis os próprios deuses. (BoRNHEIM, 1972, p. 11)

As formulações gregas posteriores do conceito e do ideal - cujo paradigma é expresso pela famosa alegoria da caverna de Platão, onde as sombras representam as formas enganosas da aparência das coisas, e os raios do sol, por sua vez, a luz da ciência - prestaram-se como base para o fortalecimento da noção e da posição do Deus judaico-cristão, que passou a ocupar o lugar da origem e destino de todas as coisas, bem como a fonte da sabedoria dos homens. Estes, feitos à sua imagem e semelhança, contariam com todos os outros seres da natureza ao seu dispor, seres estes, em contrapartida, desprovidos de alma e razão.

Assim, vemos, já no Antigo Testamento, o amplo domínio humano sobre todas as coisas criadas por Deus; em tese, uma total dissociação entre humanos e natureza. Vejamos um trecho do Gênesis: "Sejam fecundos, multipliquem-se, encham e submetam a terra; dominem os peixes do mar, as aves do céu e todos os seres vivos que rastejam sobre a terra" (GÊNESIS 1, 28).

O cristianismo, por sua vez, ensina, numa escala jamais encontrada no judaísmo, um antropocentrismo extremamente acentuado, em que o mundo todo se encontra subordinado aos objetivos do homem, 
como bem nos mostra Keith Thomas no primeiro capítulo do seu $O$ homem e o mundo natural (Thомаs, 1988).

À descoberta do espírito helênico associou-se, bem depois no século XVI, outro grande operador do pensamento científico, engendrado pelo Renascimento: a experimentação racional. Desenvolvendo o método da observação, hipótese e predição, o Renascimento "elevou a experimentação ao nível de um princípio da pesquisa como tal" (WEBER, 1993).

Dessa maneira, o desencantamento do mundo, desencadeado pelos conhecimentos astronômicos, biológicos, físicos e químicos, a partir das descobertas e experimentos de Galileu, Newton e seus seguidores endossados pelas idéias de Descartes -, dá o timbre ao pensamento moderno. Nenhum momento antes atesta como esse uma total separação entre cultura e natureza: ciência de um lado e religião de outro, razão humana e espécies naturais constituem dois hemisférios ontologicamente distintos. O progresso de tal pensamento conduziria indubitavelmente às especializações dos campos científicos conhecidos na segunda metade do século XIX e no início do seguinte.

Firmadas no bojo das definições científicas desse período, as ciências sociais encontraram sua identidade imitando os modelos da mecânica newtoniana e da evolução das espécies de Darwin, paradigmas das ciências naturais. A nascente antropologia surge através das investigações iluminadas pelo pensamento evolucionista e pautadas em um conhecimento naturalista e de fundo biologizante; embora voltadas para as sociedades primitivas, teve como preocupação última a própria sociedade européia.

\section{As sociedades primitivas: a natureza do pensamento mágico}

Na seara dos estudos com povos de outros continentes, um dos temas que animou a antropologia clássica foi aquele da relação culturanatureza: as noções de alma imanentes aos seres, a origem e retorno dos humanos às formas animais, as práticas de sacrifícios e tabus, os sistemas de classificação e toda uma imbricada rede de concepções sobre a natureza. Mesmo que sua preocupação fosse, em última instância, 
eurocêntrica, coube à antropologia trazer essa questão como sendo pensada sob outros parâmetros distintos daqueles da sociedade ocidental, racional e cristã. Muito embora a distinção entre natureza e cultura já se encontrasse nos princípios da "ciência antropológica".

As primeiras formulações podem ser identificadas nas análises de Tylor, em 1871, a partir do que denominou animismo: o princípio vital animador tanto dos seres humanos como dos animais. Tylor viu aí a noção mínima de religião, característica das tribos mais baixas na escala da humanidade. Um outro tema correlato que entrou em cena e permaneceu por muito tempo nos estudos antropológicos foi o do totemismo.

Opondo-se ao biologismo e naturalismo, as análises de Durkheim (1912) conduziram-se no âmbito da religião, associando o totemismo às regras de exogamia como elemento-símbolo da solidariedade clânica; já os estudos de Boas (1916) situam-no no bojo da pauta culturalista, em que o totemismo pode representar, nas diversas sociedades, diferentes coisas. Para as análises sociológicas de Radcliffe-Brown (1973[1929]), o fenômeno totêmico é apenas um aspecto de uma relação muito mais abrangente que as sociedades primitivas estabelecem com o mundo natural. Este, por sua vez, constitui-se de um universo regido por uma ordem moral, sendo seus habitantes governados por leis morais ou sociais e não-naturais.

Em O totemismo hoje (1980 [1962a]), Lévi-Strauss arremessa uma pá de cal em toda a reflexão até então elaborada sobre o totemismo, mostrando ser este um falso problema ao qual subjaz verdadeiramente um princípio lógico mental e inconsciente, um meio operador da relação entre cultura e natureza, mas que transcende sua simples oposição. Tal reflexão, no entanto, encontrará sua completude na obra imediatamente posterior, O pensamento selvagem (1976 [1962b]).

Segundo seu autor, o pensamento selvagem é nada mais que a exigência de ordem, característico de todo e qualquer pensamento; ele não é nem um começo, nem um esboço e nem parte de um todo ainda não realizado da evolução técnica e científica: ele forma um sistema bem articulado. Diferentemente do pensamento científico, mas articulador de princípios mentais aos moldes deste, o pensamento primitivo é um pensamento do tipo mágico. Portanto, 
em lugar de opor magia e ciência, seria melhor colocá-los em paralelo, como dois modos de conhecimento desiguais quanto aos resultados teóricos e práticos, mas não devido à espécie de operações mentais que ambos supõem e que diferem menos na natureza que na função dos tipos de fenômeno aos quais são aplicados. (LÉVI-STRAuss, 1976, p. 26)

Aí, o mito, em particular, constitui o locus privilegiado para a compreensão desse pensamento mágico, estimulado por aquilo que LéviStrauss cognominou de a "ciência do concreto". Esta, por sua vez, articula o mecanismo da reflexão entre perceptos e conceitos, intermediado na forma de ligadura pelo signo, que na união assim estabelecida desempenha o papel de significante e significado. Se por um lado a ciência cria seus meios e resultados por hipóteses e teorias, o pensamento mágico elabora estruturas organizando os fatos ou resíduos dos fatos numa forma de bricolage de idéias, estimulada pelos signos.

As duas obras anteriormente referidas constituem o prelúdio de uma orquestração ainda mais densa - embora de bases já estabelecidas por aquelas - a que Lévi-Strauss se dedicará: as Mitológicas. Estas, um conjunto de publicações entre os anos 1960 e 1970, têm como objetivo a análise de milhares de mitos das sociedades indígenas, sobretudo da América do Sul, cujo tema central é a relação entre natureza e cultura, à luz da ciência do concreto, privilegiando os valores simbólicos e cognitivos da vida social. ${ }^{2}$

Para dar fim a este extenso roteiro de autores e idéias em torno do debate antropológico sobre a relação cultura-natureza, é importante ainda mencionar as recentes abordagens de dois antropólogos americanistas, senão herdeiros pelo menos tributários do pensamento lévistraussiano: Philippe Descola e Eduardo Viveiros de Castro. O primeiro recupera a noção de animismo, que postula o caráter social das relações entre os seres humanos e não-humanos, isto é, a atribuição de características sociais aos seres naturais (DESCOLA, 1986); o segundo adota a noção de perspectivismo indígena, em que humanos e animais - subjacentes a uma ontologia multinaturalista, que advoga uma unidade do espírito e diversidade dos corpos - se diferenciam a partir de pontos de vista distintos dos sujeitos em relação (Viveiros de CAStro, 1996). 
Por outro lado, no âmbito das sociedades modernas ocidentais, vale lembrar que o historiador Keith Thomas (1988) dedica-se a revelar as diferentes formas, de proximidade e distanciamento, em que foram concebidas as relações entre homens e animais e vegetais ao longo do período moderno na Europa. E, em análises mais recentes, Bruno Latour (1997) advoga que, por mais que as sociedades modernas tenham, em teoria (ciência), se esforçado para proceder à separação entre natureza e cultura (purificação), na prática esses dois domínios sempre estiveram intrinsecamente associados (mediação): natureza e cultura constituem um híbrido a priori de qualquer processo analítico.

Em que pesem as variações e diferenças históricas das concepções de humanidade e natureza no interior da sociedade moderna, bem como suas contradições nos processos de purificação - como analisa Latour -, podemos em resumo dizer que, pelo exposto até aqui, encontramo-nos diante de dois modelos epistemológicos nos quais ancoram as teorias sobre a relação entre natureza e cultura. De um lado, o pensamento científico, característico das sociedades modernas, e, de outro, o pensamento mágico, típico das sociedades não-modernas, em particular as sociedades ameríndias.

Pretendo aqui verificar, à luz das formações epistemológicas identificadas supra, como se configuraram pensamento e prática a partir do encontro, fusão, confusão ou hibridação desses dois modelos, ou melhor, as experiências de formação cultural em que se envolveram colonizador europeu e índios - dando origem ao chamado mameluco, bem como a formação, a fortiori, de um ethos caipira -, expressas nas obras "Índios e mamelucos na expansão paulista" e Os parceiros do Rio Bonito.

\section{O encontro de duas coisas}

O colonizador que se deparou com o Novo Mundo é aquele europeu de pensamento racional científico e cristão, qualidades típicas da Europa do século XVI. Munido de cruz e espada, este civilizado encontrou-se com o nativo, cujo pensamento e prática se pautavam em referências de outra ordem. Nesse processo de embate, estranhamento e interação - conjugando interesses de ambos -, como se revela tal combinação, fertilizada que está por dois modelos distintos da praxis 
humana? Como manifesta aquilo que - por falta de outro termo, ou limitação mesmo, definida pela clássica dicotomia do pensamento científico - poderíamos chamar de interação cultura-natureza?

Sérgio Buarque de Holanda nos mostra a parceria, no seu espectro mais amplo, entre índios e colonizadores: a face da combinação que explora, povoa e civiliza o interior do Brasil; nos revela ainda que a densa e estranha paisagem tropical levou os colonizadores à imprescindível camaradagem com os tradicionais habitantes da terra. Não seria assim, afinal, que os traços de tal parceria resultariam no dito mameluco e perdurariam, como conseqüência, na cultura do homem rural brasileiro? É o que aposta o autor, respaldado por Antonio Candido em sua obra $O s$ parceiros do Rio Bonito, como veremos.

Acompanhemos, agora, alguns passos da construção do percurso que faz Sérgio Buarque em seu texto "Índios e mamelucos na expansão paulista". Não se trata de nenhuma exegese da obra e nem mesmo de explorar uma suposta concepção teórica de fundo que antevê a constituição étnica do povo brasileiro. A trajetória aqui proposta não tem outra pretensão senão a de localizar certos ingredientes para a discussão do tema escolhido, revelado pelo autor através de certas práticas de índios, brancos e mamelucos na interiorização do Brasil.

O texto de Sérgio Buarque nos aparece acessível e simples, montado todo ele por meio de referências em documentos e relatos de viajantes entre os séculos XVI e XVIII. Assim expressa o autor, de início, o que pretende:

Oposta à sociedade constituída no litoral, principalmente no litoral nordestino, nas terras do massapé gordo, onde a riqueza agrária ajudava a afinar os homens pelos gostos e às vezes até pelos requintes da Europa, essa que se cria no planalto da capitania de Martim Afonso tende a encontrar sua vocação antes no caminho, que convida ao movimento, do que no engenho de cana, que cria indivíduos sedentários. (Holanda, 1949, p. 177)

Por esses caminhos, então, partamos no encalço do colonizador e do gentio da terra. E é bem mesmo de (e por) caminhos que o autor conduz o leitor. Tais caminhos são primeiramente feitos e conhecidos dos índios que aí revelam sua técnica e cuidado, sapiência e estratégia: 
as indicações pelos galhos dobrados dos arbustos, a orientação pelo movimento do sol e da sombra durante o dia, a posição das estrelas e constelações durante a noite. A esses se somam aqueles da tradição da Península cristã: "um deles, o das cruzes de madeira chantadas nas veredas que saem das estradas gerais, a advertir o caminhante de que poucos passos depois encontrará um teto onde repouse..." (p. 180).

Vemos, aqui, pois, um curioso traço entre signos de mundos distintos. Se o nativo explora os fenômenos da natureza, o europeu lança mão de um sinal cristão-civilizador: a cruz.

Para suportar as longas caminhadas, água e alimentos deveriam estar sempre disponíveis, os trajetos deveriam prever tais fontes, e nesse sentido o texto é prolífero na descrição das formas de obtenção do que comer e beber. Com agudeza de espírito é sublinhado o conhecimento cartográficos dos nativos: o estado dos terrenos, os perigos da mata, os trajetos e comportamentos dos rios... Nessas descrições não parecem escapar formas e instantes de bricolage dos informantes, como atesta o autor no trecho abaixo:

Para tanto é indispensável a existência de uma verdadeira elaboração mental, de um poder de abstração que não se concilia facilmente com certas generalizações ainda correntes acerca da "mentalidade primitiva". O desenho chega a libertar-se, muitas vezes, da pura imagem visual. (p.183)

No traçado de picadas e estradas posteriores, a presença de boas fontes de água e rios foi vital para o estabelecimento dos primeiros arraiais e povoações: água para o abastecimento e usos caseiros e também para o funcionamento dos monjolos para beneficiamento dos produtos agrícolas.

Importante recurso da pauta alimentar e cognitiva do nativo era o mel. Várias páginas do texto de Sérgio Buarque são dedicadas ao conhecimento dos índios sobre esse produto. O manejo dos insetos apícolas, as práticas de extração dos ninhos para a criação de abelha nas aldeias, o conhecimento das diferentes espécies e seus comportamentos, as diversas utilidades do mel e da cera, os mitos e narrativas indígenas fascinavam o forasteiro e mesclavam-se com sua capacidade inventiva. 
É assim que nos adianta sobre o manejo das abelhas pelos nativos, que influenciaram incomensuravelmente a prática de exploração do mel pelos agricultores rurais em tempos ulteriores:

O hábito que ainda têm certos caipiras de São Paulo e, segundo todas as probabilidades, de outras regiões do Brasil, de trazerem de suas excursões à floresta, a fim de guardá-las junto às choças, pedaços de troncos contendo abelheiras de mandaçaia, ou mesmo simples favos, convenientemente protegidos, abrigando sementes capazes de reprodução, não constituiria herança indígena? (p. 206)

O autor nos brinda, de outra maneira, com uma curta passagem de um mito guarani sobre a origem das abelhas, enfatizando que a coleta do mel era feita sem causar danos às colméias para não ofender com isso a memória sagrada de seu antepassado derekey, a quem certa espécie apícola alimentou durante a infância. Podemos contrastar esse mito, regulador da prática de coleta do mel e manutenção dos ninhos, com aquelas práticas, correntes entre os paulistas, que usavam abundantemente a cera de abelha para confecção de velas para as festividades, exéquias e outras cerimônias religiosas.

Notamos, aqui, mais uma vez, o encontro simbólico das duas tradições: a narrativa mítica que eleva a importância do mel como fonte nutriz do herói guarani com aquela dos ritos da tradição cristã da Igreja Católica. O paralelo, sem intenção, parece ser feito pelo próprio historiador páginas adiante:

Além de realçar certas formas exteriores da liturgia católica, aquelas exatamente que mais impressionam as sensibilidades primitivas e que, por isso mesmo, convinha cultivar nestas paragens, ela concorda bem com o louvor, tradicional na Igreja de Roma, ao produto da "casta e virginal" abelha. (p. 211)

Outras fontes prodigiosas de alimentação natural são os insetos e frutos silvestres. Inúmeros são os relatos que fazem referência aos hábitos indígenas que os bandeirantes incorporaram na sua dieta pelo interior do Brasil. Em tais relatos sobressaem os usos das içás, as formigas fecundadas pelos zangões em épocas de revoadas, com seu abdome 
entumecido pela ova do inseto. Eram tão saborosas que chegavam a ser comparadas com o miolo de boi ou manteiga; e foram tão popularizadas que "seu uso tem atestado ainda em nossos dias entre algumas populações do interior, particularmente entre hervateiros e caboclos das margens do Paraná" (p. 216).

As frutas mais comuns, propagadas pela alimentação indígena aos caboclos e mamelucos, são os pinhões da araucária, jaboticabas, araçás, guarirobas, pitangas, ananases, araticuns etc. Já as espécies agricultáveis, adaptadas às condições ambientais e tecnológicas, são a mandioca, o milho e o feijão, que constituem a base alimentar de índios e brancos na expansão paulista (Antonio Candido a ela se refere, mais tarde, como formando a tríade da dieta caipira).

As modalidades de pesca, lacustre e fluvial, de influência indígena, parecem não temer competição, como lembra o autor; isto sem contar as atividades de caça, que se para o europeu representava nada mais que um nobre passatempo, para os índios era atividade de subsistência insubstituível, além de todo o seu sentido simbólico. Nesse tema também se dedica Sérgio Buarque em apresentar métodos de captura de caça, espécies apreciadas e desprezadas, técnicas e estratégias diversas que não cabem ser detalhados aqui. É preciso lembrar, também, que às técnicas nativas somaram-se os instrumentos do europeu - machados, enxadas, cunhas, anzóis, armas de fogo etc. - e a incorporação de certas espécies vegetais que bem se adaptaram ao ambiente tropical.

As atividades de caça são prolíferas em superstições que atestam a fusão de personagens e tramas, envolvendo elementos de ambas as tradições, da fé cristã e da mitologia indígena: “com o índio, nosso caçador sertanejo povoa as florestas de entidades míticas”. E é assim que aparecem histórias como a da bala de cera benta, única capaz de levar à morte o caipora, se lhe acertar o umbigo; ou o laço de rosário, que é o meio eficaz de aprisionar o saci.

Arco e flecha, além de amplamente utilizados como armas por índios e não-índios, são lembrados como apropriados para medida de distâncias: um pedaço de terra podia possuir três ou quatro tiros de flecha de comprido e dois de largura, por exemplo. Mais do que uma simples apropriação encontram-se aqui em jogo saberes e técnicas que se unem para um terceiro fim. Como diria o próprio Sérgio Buarque de Holanda: 
"A soma de elementos tão díspares gerou muitas vezes produtos imprevistos e que em vão procuraríamos na cultura dos invasores ou na dos vários grupos indígenas" (p. 236).

Dessa maneira sucedeu também com a "medicina sertaneja", um amálgama de componentes indígenas e europeus. Os preparos terapêuticos eram fabricados das mais diversas fontes vegetais e animais, como raízes, folhas, frutos, sementes ou dentes, chifres, unhas, ossos, cascos, gorduras, couraças etc. Tais componentes, entretanto, não se limitaram a ingredientes materiais, a eles se somaram crenças e tabus, amuletos e símbolos: "tão extensa e complexa foi a reunião desses elementos, que a rigor não se poderá dizer de nenhum dos aspectos da arte de curar, tal como a praticam ainda hoje os sertanejos, que é puramente indígena ou puramente europeu".

Eé assim, pois, que o autor conduz o seu texto até o fim, trazendo impressionantes relatos e outros registros de práticas de cura, e sempre tecendo tal saber "hibridizado" entre uma tradição e outra, em que já não existem "formas puras", européias ou indígenas, capazes de serem identificadas genuinamente de um ou de outro modelo de pensamento ou praxis.

Entre nossos indígenas e sertanejos, os laços que unem o homem ao mundo ambiente são bem mais intensos do que tudo quanto pode alcançar nossa imaginação. A própria arte com que sabem copiar os movimentos, os gestos, as vozes dos animais da selva, não significa neles uma simples mímica; é antes o fruto de uma comunhão misteriosa com a vida íntima da natureza. (p. 225. Grifo meu)

"Bem mais intensos do que tudo quanto pode alcançar nossa imaginação". Até que ponto o que separamos por sociedade de um lado e natureza do outro faz algum sentido em tais contextos? Só um deslocamento epistemológico parece nos permitir alcançar uma forma analítica que pressupõe a fusão de esferas tão distintamente consolidadas pela insistência do pensamento científico; ou melhor, mesmo nos domínios das cosmologias ocidentais, a distinção clássica entre natureza e cultura não deve ser utilizada sem antes passar por uma reflexão crítica rigorosa. 
Passemos à obra de Antonio Candido, encarando-a como uma extensão histórico-cultural da trajetória iniciada em "Índios e mamelucos na expansão paulista".

\section{Uma coisa de dois encontros}

O livro Os parceiros do Rio Bonito é o resultado de uma tese acadêmica - o que o torna, neste sentido, também distinto do artigo de Sérgio Buarque de Holanda. Aliado ao estilo literário, sua organização é um dos aspectos que mais impressiona o leitor. Em linhas gerais, o autor apresenta a questão que pretende analisar, "o problema dos meios de vida": como se obtém, de que maneira se ligam à vida social, como refletem as formas de organização e as de ajuste ao meio; em seguida divide a questão em três momentos: a vida caipira tradicional, a situação presente e a análise da mudança. Na verdade, trata-se de apenas dois momentos, sendo o terceiro a análise com base nos anteriores.

Cada um desses momentos, por conseguinte, é caracterizado pelas condições de subsistência, pelas formas de organização e pelas concepções de mundo vividas pelo caipira. Na primeira, a cultura caipira é apresentada, na sua forma geral, como exprimindo um tipo de economia - de subsistência e vida social - semifechada; na segunda, tomando-se como referência o estudo de caso dos parceiros do Rio Bonito, tem-se uma situação de mudança em relação ao cenário anterior, de transformação em direção a uma economia do tipo capitalista, "com manifestação de crises social e cultural". A análise da mudança, por seu turno, toma em consideração os fatos de persistência e os de alteração do equipamento material e cultural e das formas sociais da vida caipira.

O recurso metodológico para a análise da relação culturanatureza aqui empregado seguirá os passos do autor na sua estratégia de organização da obra. Isto é, se as formas de subsistência e de organização social do caipira transformaram-se sob o influxo da urbanização, alterando e mantendo certos equipamentos culturais, também suas maneiras tradicionais de concepção e interação com o meio - heranças do pensamento indígena - alteraram e mantiveram, reciprocamente, seus traços. O interesse analítico, no entanto, não são as formas de persistência 
per si, mas a possibilidade de enxergar nelas o ancoradouro através do qual se podem eleger novos parâmetros de abordagem.

A vida tradicional do caipira, tal como traçada por Antonio Candido, revela um estilo baseado na ilimitada expansão territorial, que possibilitava fácil e desimpedidamente o deslocamento e a exploração dos recursos naturais; uma organização social mínima de inevitável cooperação vicinal, cuja unidade mais abrangente é o bairro; de condições tecnológicas precárias, limitando-se a poucos bens industrializados, e em que as atividades de subsistência baseavam significativamente na caça, na pesca, na coleta e na agricultura itinerante. Como bem define o autor:

Havia entre as atividades do caipira uma correlação estreita, e todas elas representavam, no conjunto, síntese adaptativa da vida econômico-social. Assim é que o trabalho agrícola, a caça, a pesca e a coleta não eram práticas separadas, e de significado diverso mas complementares, significando cada uma per si, e todas no conjunto, os diferentes momentos dum mesmo processo de utilização do meio imediato. A roça, as águas, as matas e campos encerravam-se numa continuidade geográfica, delimitando esse complexo de atividades solidárias - de tal forma que as atividades do grupo e o meio em que elas se inseriam formavam por sua vez uma continuidade geossocial, um interajuste ecológico, onde cultura e natureza apareciam, a bem dizer, como dois pólos de uma só realidade. (p. 218)

Considerando este o perfil da sociedade caipira, tal concepção matricial parece ser assim estendida pelo autor para suas abordagens dos diferentes campos da vida social, econômica e cultural. Dessa maneira, a economia do tipo fechada, com base no trabalho isolado e na cooperação ocasional, é caracterizada pela manifestação de formas primárias que permitiram estabilizar as relações com o meio mediante o conhecimento e a exploração satisfatórios dos recursos naturais.

Tais formas primárias de equilíbrio, segundo o autor, são traços da herança indígena, encontrando-se em associação um mínimo vital a um mínimo social: alimentação suficiente para sustentar a vida e organização social limitada à sobrevivência do grupo. Uma agricultura de corte-e-queima caracterizava-se pelo cultivo do feijão, do milho e da 
mandioca: o "triângulo básico da alimentação caipira"; a caça de animais silvestres, por seu turno, era a atividade básica de subsistência por excelência, garantindo todo o suprimento de carne necessária.

Associada a essas atividades de subsistência, as formas de solidariedade limitavam-se à ajuda mútua entre pessoas e famílias de um mesmo bairro, embalada pelo espírito religioso, festivo e gratuito. Em resumo, ao mínimo social, encerrado na vida do bairro - abaixo do qual se teria anomia -, correspondia um mínimo vital - aquém do qual se teria fome - representado pela dieta básica do triângulo alimentar.

Vimos, pois, que a vida tradicional caipira, analisada por Antonio Candido, ancora-se, primeiramente, naquele cenário interpretado por Sérgio Buarque de Holanda, para quem o aproveitamento dos recursos naturais manifesta-se "com fins de ajuste ao meio, sob o ritmo da fusão de raças e culturas". A esse critério, soma-se aquele - característico das abordagens da ecologia cultural cujo determinismo ambiental é definidor dos padrões culturais ${ }^{3}$ - que estabelece a equação necessária entre ajuste ao meio e organização social caipira.

Independentemente das chaves teóricas interpretativas escolhidas pelo autor de Os parceiros do Rio Bonito, a cultura tradicional caipira aparece como eivada por uma prática fertilizada pelo pensamento do tipo mágico entre sociedade e natureza, conforme atesta o próprio autor nesta maravilhosa sentença:

Magia, medicina simpática, invocação divina, exploração da fauna e da flora, conhecimentos agrícolas fundem-se deste modo num sistema que abrange, na mesma continuidade, o campo, a mata, a semente, o ar, o bicho, a água e o próprio céu. Dobrado sobre si mesmo pela economia de subsistência, encerrado no quadro dos agrupamentos vicinais, o homem aparece ele próprio como segmento de um vasto meio, ao mesmo tempo natural, social e sobrenatural. (p. 220)

Uma vez traçado o panorama geral da cultura caipira, Antonio Candido dedica-se, a partir daí, a definir quem são os parceiros do Rio Bonito, universo objetivo de sua investigação. Este é, antes de mais nada, um universo já transfigurado, conforme exposto acima, e, apesar disso - 
e este é o interesse do autor em demonstrar -, a comunidade de parceiros analisada guarda vincados traços da velha feição caipira.

Tanto no âmbito do município de Bofete quanto da fazenda onde residem os parceiros, o quadro é de um "interessante confronto", de transformações econômicas, técnicas e culturais, de coexistência entre a monocultura e a agricultura de subsistência, o latifúndio e o sítio, o imigrante e o caboclo; enfim, entre o presente e o passado. O que torna a situação privilegiada para a pesquisa das mudanças sofridas pela vida tradicional do caipira.

O norte perseguido pelo autor continua sendo aquele de uma estrutura elementar dada pela relação entre o mínimo vital e o mínimo social. Significa dizer que, em torno desta, são analisados a estrutura fundiária da região, o desenvolvimento urbano, a dinâmica de mercado regional, a população rural e os sistemas de parceria, o regime de trabalho, as atividades de subsistência, a dieta caipira etc. Em resumo, conforme o veredito do próprio autor, a realidade observada e comparada àquela da tradição caipira é

de um acentuado incremento de dependência, que destrói a autonomia do grupo de vizinhança, incorporando-o ao sistema comercial das cidades. E, ao mesmo tempo, uma perda ou transferência de elementos culturais, que antes caracterizavam a sociedade caipira na sua adaptação ao meio. (p. 178)

Não cabe aqui discorrer sobre os detalhes da mudança em cada um dos aspectos levantados, mas apenas sobre aqueles da relação cultura-natureza que se revelam nesse cenário de mudança apresentado.

Com exceção da agricultura, as demais atividades de subsistência tornaram-se esporádicas e secundárias. Assim, por exemplo, a caça limitou-se ao entorno e em defesa das roças; se antes se produzia quase tudo o que se consumia, agora foi preciso vender boa parte do que se plantava para comprar o que comer. Consequiência imediata disso, segundo o autor, foi a perda de hábitos alimentares tradicionais e uma estabilização em níveis equivalentes aos padrões mais baixos do passado imediato, alcançando em alguns casos, a situação de fome. 
Diante desse quadro, que tipo de interação cultura-natureza podemos ressaltar? Vimos que a prática agrícola tornou-se a atividade por excelência, requerendo maior dedicação do caipira. Dessa maneira, sob condensada atenção, o universo agrícola constituiu-se num campo totalizador - digamos, uma espécie de fato social total - da interação direta e imediata dos domínios da cultura e da natureza, como se depreende do que segue:

O ritmo da sua vida é determinado pelo dia, que delimita a alternativa de esforço e repouso; pela semana, medida pela 'revolução da lua', que suspende a faina por vinte e quatro horas, regula a ocorrência das festas e o contato com as povoações; pelo ano, que contém a evolução das sementes e das plantas. A sua atividade favorece a simbiose estreita com a natureza, funde-o no ciclo agrícola, submetendo-o à resposta que a terra dará ao seu trabalho, que é o pensamento de todas as horas. (p. 156)

Em suma, esse ritmo de vida determinado quase que exclusivamente pela agricultura canaliza o conjunto das construções simbólicas, dada a observação sagaz do ciclo vegetativo das espécies em cada detalhe de sua dinâmica. Em outras palavras, significa dizer que as plantas cultivadas - ou o cultivo das plantas - puderam constituir-se num excelente estoque de matéria-prima - signos, metáforas, temporalidades, ritmo etc. - do idioma social. Isto é, as espécies não são boas apenas para comer, mas para pensar, como bem disse Lévi-Strauss no âmbito das classificações totêmicas. Aqui, então, teríamos uma "totemização" da vida social caipira.

A natureza dessa observação conduz ainda o homem rural caipira à organização dos acontecimentos sociais dos quais participa, como as festas de santo. Temos, desse modo, uma clara imbricação das dimensões natural, social e sobrenatural, em que o tempo é marcado pelo desenvolvimento das plantas e dos eventos religiosos - o que nos estimula a perguntar mais uma vez até que ponto a separação desses (ou nesses) universos nos ajudam a compreender de forma mais sábia a relação cultura-natureza. Vejamos: 
Para o caipira, o ano começa em agosto, com o início das operações de preparo da terra; e termina em julho, com as últimas operações de colheita. [...] Marcando esta divisão especial do ano segundo o ritmo agrário, devemos lembrar a festa de São João, a 24 de junho, que o encerra; e a 16 de agosto a de São Roque, importante em toda essa região do estado, que o inicia, carregada de votos e esperanças relativas à labuta que se reabre. (p. 158)

Outras prescrições ainda seguidas pelos caipiras são aquelas de restrições alimentares que incluem práticas como a dieta de parto - sob a qual a mulher deve passar algumas dezenas de dias à base de caldo de galinha e obedecendo a certas misturas de alimentos -, bem como de abstinência religiosa.

Na terceira e última parte de seu livro, no que denominou "análise da mudança", Antonio Candido aborda a situação de crise sofrida nos diferentes campos da vida dos parceiros, verificada tanto em 1948 quanto em 1954, os dois momentos do seu trabalho de campo. Para tal análise, organizou os temas em relações de trabalho e comércio; ajuste ecológico; técnicas, usos e crenças; posição e relações sociais e representações mentais.

Cada um desses, por seu turno, é submetido a uma rigorosa leitura crítica aferida pela comparação entre o presente e o que fora antes, tanto em termos da situação tradicional do caipira como das condições concretas da vida dos parceiros do Rio Bonito. Embora cada campo apresente suas características de mudanças, a base da crise é representada pelo processo de urbanização e industrialização a que foram submetidas a região e a vida do homem do campo.

Hoje, a dimensão econômica avultou até desequilibrar a situação antiga. A expansão do mercado capitalista não apenas força o caipira a multiplicar o esforço físico, mas tende a atrofiar as formas coletivas de organização do trabalho (mormente a ajuda mutua), cortando as possibilidades de uma sociabilidade mais viva e de uma cultura harmônica. (p. 213)

Se, por um lado, a bagagem da cultura material tem a sua alteração visível e às vezes de fácil mensuração, o equipamento simbólico, 
por outro, não se esvanece no mesmo ritmo, além de constituir-se de formas mais maleáveis às combinações. É o que acontece com os domínios das festividades, das crenças religiosas e da terapêutica mágica. No plano da relação sociedade-natureza, identificada como de "ajuste ecológico", Antonio Candido analisa-o, à luz da mudança, como ressignificado e ajustado pela intermediação do trabalho, a força humanizadora da natureza:

Esta familiaridade do homem com a natureza vai sendo atenuada, à medida que os recursos técnicos se interpõem entre ambos, e que a subsistência não depende mais de maneira exclusiva do meio circundante. $\mathrm{O}$ meio artificial, elaborado pela cultura, cumulativo por excelência, destrói as afinidades entre homem e animal, entre homem e vegetal. Em compensação, dá lugar à iniciativa criadora e a formas associativas mais ricas, abrindo caminho à civilização, que é a humanização. (p. 221)

Vemos, aqui, pois, que a relação cultura-natureza é tratada no plano da adequação do grupo às condições do ambiente. Dessa maneira, a dimensão do "ajuste ecológico" não se encontra nem no âmbito das condições materiais da cultura nem naquele dos equipamentos simbólicos, mas parece situar-se a meio caminho entre um e outro. Enfim, a relação cultura-natureza é dinamizada menos pelas estruturas mentais e mais pelas condições de transformação do meio, operada pelas forças produtivas.

Para terminar, lembremos que o autor de Os parceiros do Rio Bonito reservou, de forma especial, um tópico dedicado às "formas de persistência da cultura caipira", que em tom de conclusão propositiva destaca:

Encarando em conjunto a situação estudada, podemos defini-la como resultante da coexistência dos fatores de persistência e dos fatores de transformação. É a ação de ambos que de fato a caracteriza, emprestando ao seu panorama certa alternância de equilíbrio e uma incessante mobilidade, onde se vêem predominar ora uns, ora outros, mas onde ambos se encontram sempre presentes. (p. 252) 
Assim, após definir o que entende por persistência e transformação - em que os fatores tradicionais exercem ação reguladora, combinando e integrando aos novos -, o autor elege cinco traços, ligados aos aspectos econômicos, da preservação do modelo tradicional caipira, analisando-os: 1) apego às formas de parceria; 2) mobilidade no espaço; 3) vizinhança; 4) solidariedade de vizinhança e 5) caráter complementar dos bairros.

Podemos dizer que por todos esses traços da economia perpassou o fio condutor da dimensão cultura-natureza, sob análise neste ensaio.

Qualquer tentativa de conclusão deste ensaio parece não combinar com seu objetivo. Pelo contrário, ele é de todo introdutório, tratando-se, conforme disse no seu início, nada mais que de um experimento. Seguem, no entanto, algumas considerações finais para não parecer este exercício tão aberto e sem propósito. Retomemos alguns pontos.

As análises de Lévi-Strauss sobre os sistemas de classificação indígena - privilegiadamente em $O$ pensamento selvagem - estabelecem um claro paralelo entre a ciência moderna e a ciência primitiva, ambas resultado de operações mentais, exercício do espírito humano. Bem depois, ainda em História de Lince, o autor reforça seu primado da relação: "do modo mais inesperado, é o diálogo com a ciência que torna o pensamento mítico novamente atual". (Lévi-STRAUSS, 1993 [1991], p. 12). De outro lado, vimos em Latour (1994) um enfoque sobre as ciências modernas, que se esforçam continuamente na separação de algo - cultura e natureza -, que, por ordem da imanência prática, é indissociável e que por isso pouco ou nada difere das demais sociedades não-ocidentais; ou seja, "nunca fomos tão modernos": o mundo não estaria tão desencantado como sempre propagou a ciência.

Assim, temos, no primeiro autor, uma aposta na semelhança entre os pensamentos - dadas suas operações, imanentes ao espírito humano - entre sociedades primitivas e modernas, e no segundo uma aproximação entre sociedades modernas e não-modernas menos em teoria (pensamento), mas efetiva na ordem da prática. 
Talvez este ensaio pretendesse ser - e só agora me dou conta disso - uma viagem em ziguezague por essas duas vias, atentando para o pensamento e prática (ambos como indissociáveis) da relação entre cultura e natureza. Dessa forma, índio, europeu, mameluco, caipira como mostrados nas obras em apreço - aparecem como personagens de uma trama que nos possibilita pensar os domínios rotulados de natureza e cultura sob outros ângulos. Não que natureza e sociedade sejam uma e só coisa, mas que tais domínios não podem ser tomados como posições fixas e determinadas a priori, como campos ontológicos distais e impermeáveis.

Longe de uma busca arqueológica de vestígios de um passado original, tratou-se aqui de ver - no caso particular da formação histórica da cultura caipira - não os traços que permaneceram como substantivos de uma tradição, mas de notar alguns elementos que permitiram enfrentar o desafio da relação entre sociedade e natureza: escapar do olhar imobilizador - como nos sugere o personagem do mito grego no seu embate com a medusa assassina - que opõe visceralmente esses dois domínios.

\begin{abstract}
Despite of their different styles and purposes, "Índios e mamelucos na expansão paulista", by Sérgio Buarque de Holanda, and Os parceiros do Rio Bonito, by Antonio Candido, present two epistemological patterns, on which the theories about the relation between nature and culture base on - the magic thought, typical of the non-modern societies, and the scientific thought which characterizes the modern societies.
\end{abstract}

Key words: Social groups, nature, culture.

\title{
Agradecimentos
}

Devo meus agradecimentos a Lilia Moritz Schwarcz e a Fernanda Peixoto pela leitura atenta e pelas sugestões imprescindíveis. 


\section{Notas}

1. As obras aqui tomadas como referências são "Índios e mamelucos na expansão paulista", publicada nos Anais do Museu Paulista, tomo 13, de 1949; e Os parceiros do Rio Bonito, 9.ed. São Paulo: Editora 34, 2001.

2. Um evidente contraponto analítico das Mitológicas é a vertente teórica da ecologia cultural - fundada no Handbook of South American Indians, editado por Julian Steward entre 1946 e 1950 -, cujo enfoque está voltado para as condições materiais de produção e para o determinismo ambiental sobre o desenvolvimento da cultura. Nessa linha, uma série de estudos foi desenvolvida na Amazônia, a exemplo de Meggers (1954 e 1977 [1971]), Carneiro (1961), Gross (1975), entre outros.

3. A publicação do Handbook of South American Indians, referência primeira das abordagens da ecologia cultural, aparece entre o final dos anos 1940 e início de 1950 e certamente iluminou as análises de Antonio Candido, que a ele se refere em nota de rodapé na introdução teórico-metodológica de Os parceiros do Rio Bonito.

\section{Referências}

Boas, F. The origin of totemism. American Anthropologist, n. 18, 1916.

BornHEIM, Gerd A. Introdução. Os filósofos pré-socráticos. 2.ed. São Paulo: Cultrix, 1972.

Candido, Antonio. Os parceiros do Rio Bonito: estudo sobre o caipira paulista e a transformação dos seus meios de vida. São Paulo: Editora 34, 2001 [1964].

CARneIro, R. Slash-and-burn cultivation among the Kuikuro and its implications for cultural development in the Amazon Basin. In: WILBERT, J. (Ed.). The evolution of horticultural systems in native South America: causes and consequences. Caracas: Sociedad de Ciencias Naturales La Salle, 1961. p. 47-64.

Descola, Philippe. La nature domestique: symbolisme et praxis dans l'ecologie des Achuar. Paris, 1986.

DuRKHeIM, E. Les formes élémentaires de la vie religieuse, 1912.

Gross, D. R. Protein capture and cultural developmente in the Amazon Basin. American Antropologist, v. 77, n. 3, p. 526-549, 1975. 
Holanda, Sérgio Buarque. Índios e mamelucos na expansão paulista. Anais do Museu Paulista, tomo 13, 1949.

LATOUR, B. Jamais fomos modernos: ensaios de antropologia simétrica. São Paulo: Editora 34, 1994.

LÉvi-Strauss, C. O totemismo hoje. 2.ed. São Paulo: Abril Cultural, 1980 [1962a]. (Coleção Os Pensadores).

b].

. O pensamento selvagem. 2.ed. São Paulo: Nacional, 1976 [1962

. Mythologiques. v. 1-4. Paris: Plon, 1964-1971.

[1991].

História de Lince. São Paulo: Companhia das Letras, 1993

MegGers, B. Enviromental limitations on the development of culture. American Anthropologist, v. 56, n. 5, p. 801-824, 1954.

. Amazônia: a ilusão de um paraíso. Rio de Janeiro: Civilização Brasileira, 1977 [1971].

RadClifFe-Brown, A. R. Estrutura e função nas sociedades primitivas. Petrópolis: Vozes, 1973 [1929].

Ronan, Colin. História ilustrada da ciência. Rio de Janeiro: Jorge Zahar, 1997 [1984]. 4 v.

Ross, Eric. Food taboos, diet, and hunting strategy: the adaptation to animals in amazon cultural ecology. Current Anthropology, v. 19, n. 1, p. 1-36, 1978.

Thомаs, Keith. $O$ homem e o mundo natural: mudança de atitude em relação às plantas e aos animais (1500-1800). São Paulo: Companhia das Letras, 1988.

TyloR, Edward B. Primitive culture: animism. Editados por Amer. The Modern Library, Inc. 1931 [1871].

Viveiros de CAstro, E. Os pronomes cosmológicos e o perspectivismo ameríndio. Mana. v. 2, n. 2, 1996.

Weber, M. A ciência como vocação. Ciência e política: duas vocações. São Paulo: Cultrix, 1993. 